\title{
EXPERIMENTAL STUDY ON POOL BOILING HEAT TRANSFER PERFORMANCE OF MAGNESIUM OXIDE NANOPARTICLES BASED WATER NANOFLUID
}

\author{
${ }^{1,3}$ Mohammed Saad KAMEL ${ }^{*}{ }^{2}$ Ferenc LEZSOVITS \\ ${ }^{1,2}$ Department of Energy Engineering, Faculty of Mechanical Engineering \\ Budapest University of Technology and Economics, 1111 Budapest \\ Mủegyetem rkp. 3, Hungary, e-mail: ${ }^{1}$ kamel@energia.bme.hu, ${ }^{2}$ lezsovits@energia.bme.hu \\ ${ }^{3}$ Department of Mechanical Techniques, Al-Nasiriya Technical Institute, Southern Technical \\ University, 64001 Thi-Qar, Baghdad Street, Iraq, e-mail: kame186@stu.edu.iq
}

Received 29 December 2019; accepted 9 April 2020

\begin{abstract}
This study aims to experimentally investigate the nucleate pool boiling heat transfer performance of magnesium oxide nanoparticles $\mathrm{MgO}$ based deionized water nanofluid at the atmospheric pressure condition. Dilute volumetric concentrations within a range of $0.001 \%$ to $0.01 \%$ Vol. were used to examine the pool boiling heat transfer performance represented by pool boiling curve, and pool boiling heat transfer coefficient. The heating element was a horizontal copper heated tube with a typical diameter $22 \mathrm{~mm}$ submerged inside the cubic boiling chamber. Efforts have been made to measure the surface temperatures along the heated tube to ensure the proper and accurate heat transfer coefficient calculations in this work. The results indicated that the pool boiling heat transfer coefficient enhancement ratio $\left(\mathrm{PBHTC}_{\mathrm{nf}} / \mathrm{PBHTC}_{\mathrm{water}}\right)$ was intensified for volume fractions i.e. $0.001 \%, 0.004 \%$, and $0.007 \%$ Vol. while it was degraded for volume concentrations i.e. $0.01 \%$, and $0.04 \%$ Vol. compared to deionized water as baseline case.
\end{abstract}

Keywords: Pool boiling, Magnesium oxide, Nanofluids, Pool boiling heat transfer coefficient, Enhancement ratio

\section{Introduction}

Boiling heat transfer and two-phase flow plays a significant role in many heat exchange systems. Boiling heat transfer mode is an efficient mode among other heat transfer modes, and this is due to the latent heat of vaporization that occurred during boiling phase change [1]-[5]. Recently, there is an increasing demand to develop new products with high efficiency and compact space for saving thermal energy. To achieve

\footnotetext{
${ }^{*}$ Corresponding Author
} 
that, efficient cooling liquids should be used to meet the requirements by removing high heat dissipation in a relatively small temperature difference. Nanofluids are a new class of thermal fluids that made from dispersing solid nanoscale materials with a range of 1-100 $\mathrm{nm}$ and those solids materials have thermal conductivity better than the thermal conductivity of base fluids [6]-[11]. Numerous investigators have been studied the pool boiling of nanofluids with different operating conditions to understand the mechanism thoroughly. Yang and Maa [12] conducted early in 1986 a careful experimental study to clarify the behavior of pool boiling heat transfer using dispersed alumina solid particles with a dilute concentration between 0.1-0.5 wt.\%. Their results demonstrated an enhancement in pool boiling heat transfer using alumina particles compared to the conventional fluid. Das et al. [13] experimentally studied the effect of adding alumina nanoparticles based water nanofluid on the behavior of the pool-boiling curve and heat transfer coefficient from narrow horizontal heated tubes. Results have been shown that the mechanism of pool boiling is different from small tubes to those of typical industrial pipes due to the sliding of bubbles from the bottom part to the upper region. They also demonstrated that the pool boiling performance decreased while adding those nanoparticles. Trisaksri and Wongwises [14] carried out an experimental study to investigate the pool boiling heat transfer performance of titanium oxide nanoparticles $\mathrm{TiO}_{2}$ based R141b nano-refrigerant. They utilized a cylindrical copper heated tube as a heating element in their test. Results show that the heat transfer coefficient was degraded with increasing particle concentration especially for high heat flux. Again, Suriyawong and Wongwises [15] studied the pool boiling performance of $\mathrm{TiO}_{2}$ nanoparticles based water nanofluid at various volume concentrations. They used two types of heating surfaces (copper and aluminum tubes) in their study with different surface roughness. Their results demonstrated that the Pool Boiling Heat Transfer Coefficient (PBHTC) was enhanced for a copper tube with a concentration of $0.0001 \%$ Vol., while there was degradation with aluminum tube.

Cieśliński and Kaczmarczyk [16] investigated the pool boiling heat transfer performance of two types of nanofluids so-called $\left(\mathrm{Al}_{2} \mathrm{O}_{3}\right.$, and $\mathrm{Cu}$ nanoparticles based water nanofluids). They used a horizontal smooth copper and stainless steel tubes as a heating element in their tests. Nanoparticles were loaded with a concentration in a range of $0.01-1$ wt.\%. Their obtained results show that the concentration of nanofluids has almost no influence on the pool boiling heat transfer coefficient. In contrast, the higher heat transfer coefficient was recorded for stainless steel tube compared to the copper tube for the same applied heat flux. In another work, Cieśliński and Kaczmarczyk [17] examined the influence of operating pressure 200,100 , and $10 \mathrm{kPa}$ on two types of nanofluids during pool boiling process. Their results revealed that independent of nanoparticle materials $\left(\mathrm{Al}_{2} \mathrm{O}_{3}\right.$ and $\left.\mathrm{Cu}\right)$ and their concentration, while an increase in operating pressure enhanced the heat transfer performance.

Ahmed and Hamed [18] conducted experiments to study the pool boiling from a horizontal flat copper surface for $\mathrm{Al}_{2} \mathrm{O}_{3} 40-50 \mathrm{~nm}$ water-based nanofluids within a range of concentrations of 0.01-0.5 Vol. Nanofluids boiling tests have been followed by pure water boiling tests on the same nanoparticle-deposited surfaces. Their results show that the boiling of pure water on a nanoparticle-deposited surface formed using the highest concentration nanofluid resulted in the highest heat transfer coefficient. Sarafraz and Hormozi [19] carried out an experimental study to study the pool boiling heat transfer 
using aqueous multi-walled carbon nanotubes nanofluids for modified heater surfaces up to the critical heat flux limit. Several surface properties with diamond-shaped microfinned have been examined during their investigation; their results showed that the pool boiling heat transfer coefficient on the plain surface was degraded. While for microfinned surfaces, it was improved up to $56 \%$ and $77 \%$ for 0.1 and $0.3 \%$ mass concentration, respectively. However, the formation of a fouling layer at the heater surface observed, which created a vast thermal resistance layer and a significant decrease in the heat transfer coefficient. Kiyomura et al. [20] studied the effects of surface roughness and nanoparticle deposition on the contact angle, surface wettability, and pool boiling heat transfer coefficient. They reported that increase the concentration of magnetite nanoparticles used in their study increased the surface roughness of the heating surface. Besides, the highest heat transfer coefficient was obtained for the smooth surface with the deposition of nanoparticles at low mass concentrations. Karimzadehkhouei et al. [21] investigated the pool boiling of two types of nanofluids $\mathrm{TiO}_{2}$ based water and $\mathrm{CuO}$ based water on the discoid copper heater at atmospheric pressure condition. Their results have shown that for $\mathrm{TiO}_{2}$ based water nanofluids, the pool boiling heat transfer coefficient was increased at dilute volume fraction i.e. $15 \%$ at $0.001 \%$ wt. Besides, the $\mathrm{CuO}$ based water nanofluid pool boiling heat transfer coefficient was about $35 \%$ compared to water as a baseline case.

In the present work, the pool boiling heat transfer performance using deionized water and magnesium oxide nanoparticles $\mathrm{MgO}$ based deionized water has been experimentally investigated at atmospheric conditions. Various dilute volume concentrations of nanofluid within a range of $0.001 \%$ to $0.01 \%$ Vol. at different values of applied heat flux were used to examine the pool boiling heat transfer performance represented by pool boiling curve, pool boiling heat transfer coefficient, and pool boiling heat transfer coefficient ratio of nanofluids relative to deionized water. Therefore, this investigation contributes to assessing this new type of nanofluids with dilute volume concentration as a working fluid during the pool boiling heat transfer process.

\section{Experimental setup}

The pool boiling facility and the instruments in the present investigation were schematically shown in Fig. 1. The test loop consists of the pool boiling chamber with dimensions: Length $=155 \mathrm{~mm}$, Width $=120 \mathrm{~mm}$, Height $=310 \mathrm{~mm}$. Fireproof ceramic glass (from Poly M Hungary Ltd.) was used to visualize the bubble dynamics during pool boiling experiments. The pool boiling chamber was insulated via two insulation materials layers; the first layer was an insulation sheet with high reflective one side material from solflex (Thermofoam company, OBI store, Hungary), the second one was the $10 \mathrm{~mm}$ thermal insulation sheet to minimize heat losses from the chamber. Cooling condenser (Type: Allihn cooling condenser) supplied from (aalabor.hu) used to condense the vapor to liquid phase and keep the atmospheric pressure condition; therefore, to ensure the fluid capacity do not reduce inside the apparatus during the experiments. The major part of this facility is the heating element, which is a horizontal copper heated tube with an external diameter $22 \mathrm{~mm}$ and thickness $1 \mathrm{~mm}$ filled with 
copper sleeve fabricated in our laboratory. The copper sleeve was machined to make three grooves along with the axial distance with different radial angles and locations. Four K-Type thermocouples were calibrated and used to measure the surface and bulk temperatures. Great efforts have been made to fix the thermocouples in a proper way to measure the surface temperatures. Stainless steel cartridge heater with a power $1 \mathrm{~kW}$ and diameter $12.5 \mathrm{~mm}$, length $100 \mathrm{~mm}$ manufactured by (Cartridge heaters, UK) inserted to the copper sleeve to supply the heat flux. All abovementioned parts were designed, fabricated, and collected to build up our pool boiling apparatus at the laboratory of the Department of Energy Engineering at (Budapest University of Technology and Economics, Hungary).

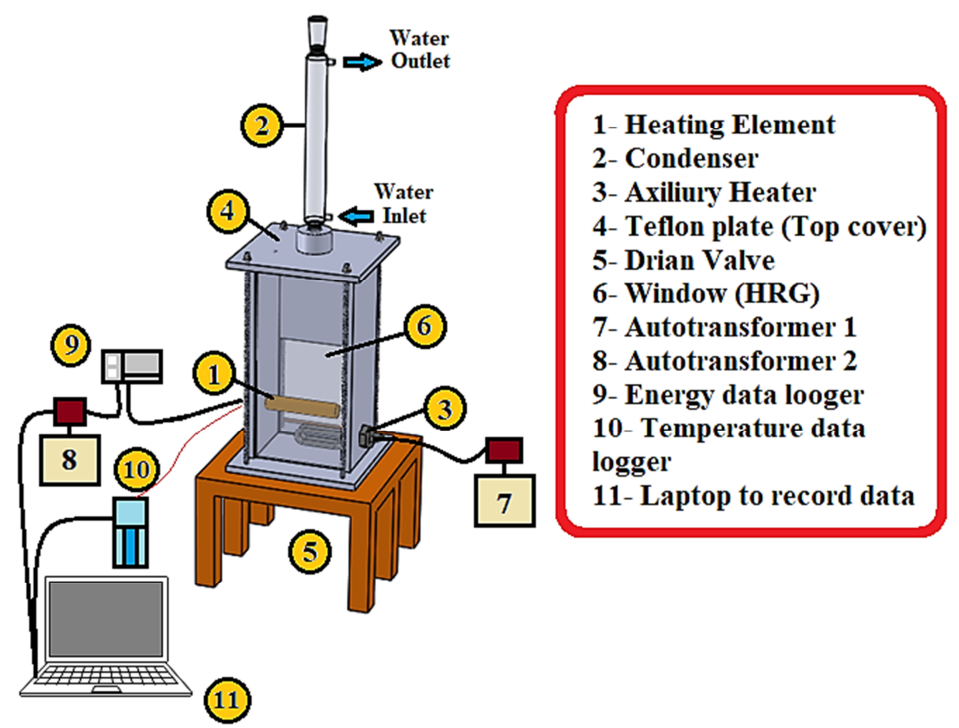

Fig 1. Schema of pool boiling apparatus and measurement facility

\section{Nanofluid preparation method}

The preparation of nanofluids is considered as a crucial stage during the nanofluids experimental studies. The two-step method is widely used in the preparation of nanofluids by mixing the conventional fluid (i.e. water, ethylene glycol, oil etc.) with commercially available nanomaterials that obtained from several physicals, mechanical and chemical process [7], [22]. In the present work, deionized water and magnesium oxide nanoparticles are prepared by adopted two-step method to investigate the pool boiling heat transfer performance. The two-step method was applied in this study to make the nanofluids at various dilute volume concentrations (0.001 up to $0.04 \mathrm{Vol}$.\%). In this regard, the first step is to weight the desired quantity of the dry nanopowder via accurate digital balance, which has an accuracy of 0.001 grams. The scaled amount of 
nanopowder was added and mixing to a desired volume of the water. Next, the amount of nanopowder mixed with deionized water by means physical methods like stirrer and ultra-sonication process. Finally, the stability of prepared suspensions was checked via the sediment-time method, and the final suspension used for the purpose of boiling heat transfer application. Fig. 2 presents the stability of the suspension after a period of the sonication process.

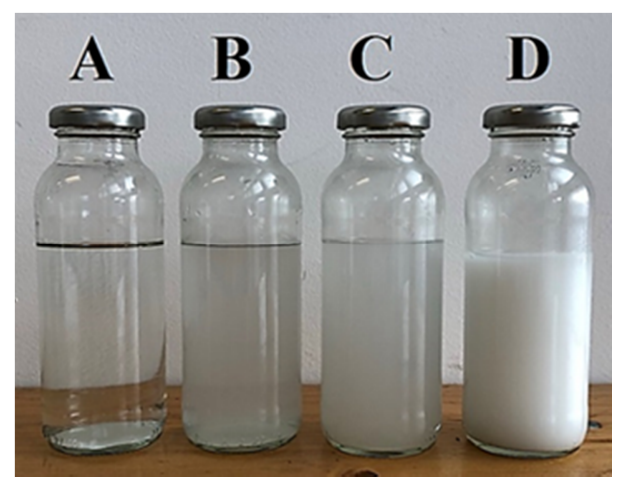

After (1 hour) of sonication

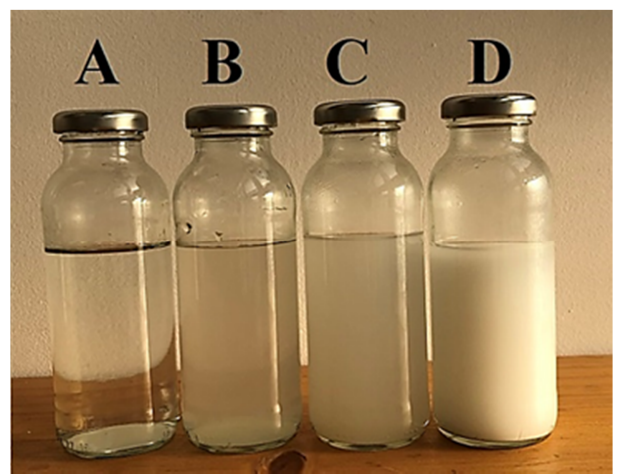

After (2 days) of sonication

Fig. 2. Stability of $\mathrm{MgO}$ based deionized water nanofluids at different periods, A) deionized water; B) $0.001 \%$ Vol.; C) $0.004 \%$ Vol.; D) $0.04 \%$ Vol.

\section{Experimental procedure}

The following steps are applied during the test of pool boiling heat transfer using deionized water and $\mathrm{MgO}$ nanoparticles based deionized water nanofluid:

1. First, the pool boiling chamber and the heating element (horizontal heated copper tube) were cleaned and washed using acetone and water jet before each test;

2. The working fluid (deionized water or nanofluid) was injected from the top of the chamber via the injection hole for such purpose;

3. The added working fluid was preheated by using auxiliary heater $400 \mathrm{~W}$ until the liquid reaching the saturation temperature, then the heater kept switch on with maximum power for $5 \mathrm{~min}$ to remove all unnecessary degassing bubbles inside the pool boiling;

4. The central heater (horizontal heated copper tube) was switched on, and it is power gradually increased to reach the maximum potential for our cartridge heater and then start to decrease at stepwise to calculate the applied heat flux;

5. The power of the central heater, the surface temperatures, and the bulk temperature was recorded via software instilled on a personal computer;

6. The runs for deionized water as baseline case and as well as a validation case for the boiling apparatus were repeated three times to check the repeatability of the measurements, and they were found to be acceptable. 


\section{Results and discussion}

\subsection{Validation of pool boiling chamber}

The pool boiling heat transfer experiment was firstly conducted for deionized water as a baseline case and also to validate the setup and shows the reliability of the boiling chamber. Therefore, the results of pool boiling curves for deionized water compared to those well-known correlations in literature so-called Rohesnow correlation [23], and Gorenflo correlation [24], and some experimental works reported in the literature as Das et al. [13], and Suriyawong and Wongwises [15]. The reason behind using deionized water for the validation for obtained results that this type of liquids has well-known and high accurate thermophysical properties in literature [25]. Hence, the experimental results for deionized water plotted as it can be seen in Fig. 3 and the experimental results compare reasonably well with predicted correlations as well the experimental studies for pool boiling curves.

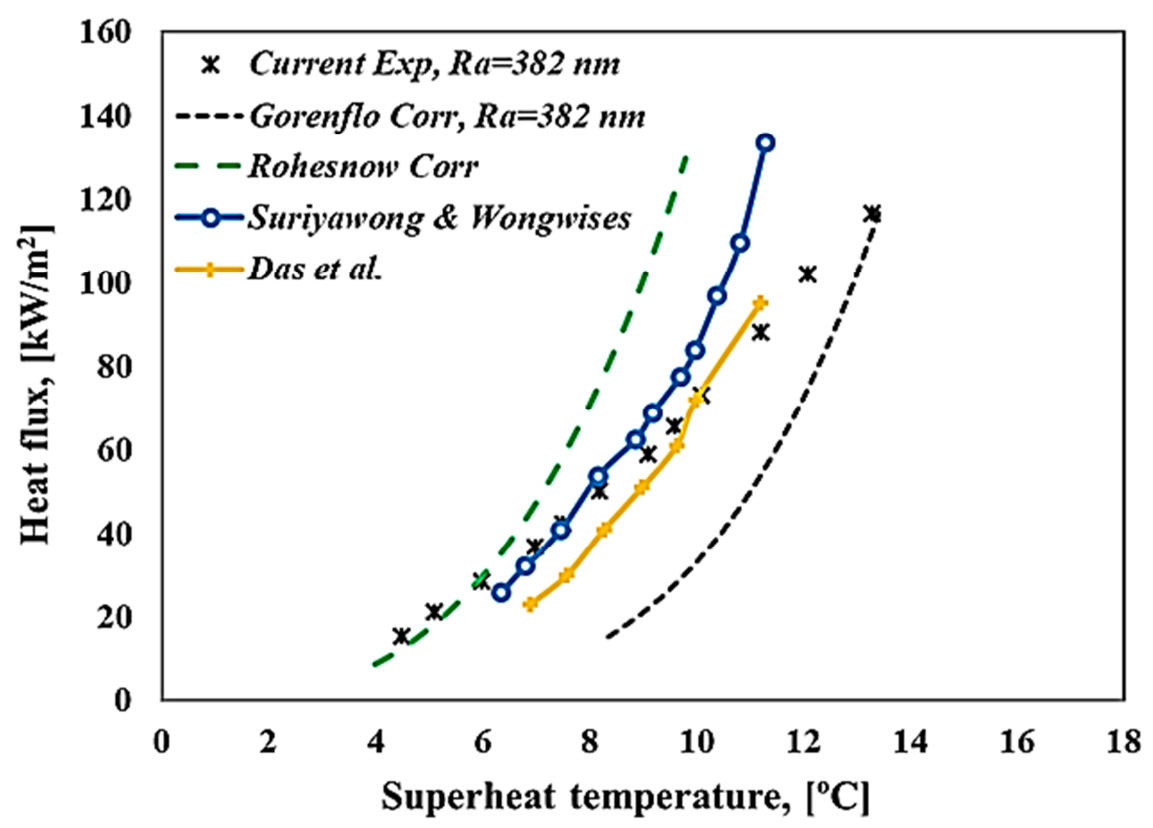

Fig. 3. Validation of pool boiling curves for deionized water for present data and some related data in the literature

\subsection{Pool boiling of nanofluid results}

Pool boiling heat transfer performance using magnesium oxide $\mathrm{MgO}$ nanoparticles based deionized water from the horizontal heated copper tube was experimentally investigated. Different dilute volume concentrations with a range of $0.001 \%-0.04 \%$ Vol. were considered for preparing the nanofluids. The surface roughness of the heated copper tube was measured by surface roughness tester and the arithmetic average 
roughness $R_{a}=0.382 \mu \mathrm{m}$. Fig. 4 shows the pool boiling curve represented by the heat fluxes against the superheat temperatures for deionized water as a baseline case and for magnesium oxide-based deionized water nanofluids. It can be seen that the pool boiling curves for dilute concentrations i.e. $0.001 \%, 0.004 \%$, and $0.007 \%$ Vol. were shifted to the left side of the deionized water pool boiling curve, and this means that the pool boiling heat transfer was enhanced by reducing the superheat temperatures as same heat fluxes values. However, an increase in volume concentration of magnesium oxide nanofluids i.e. $0.01 \%$ and $0.04 \%$ Vol. noticeably, the boiling curves were shifted to the right side, and this change was notable especially in high heat flux regions above $60 \mathrm{~kW} / \mathrm{m}^{2}$.

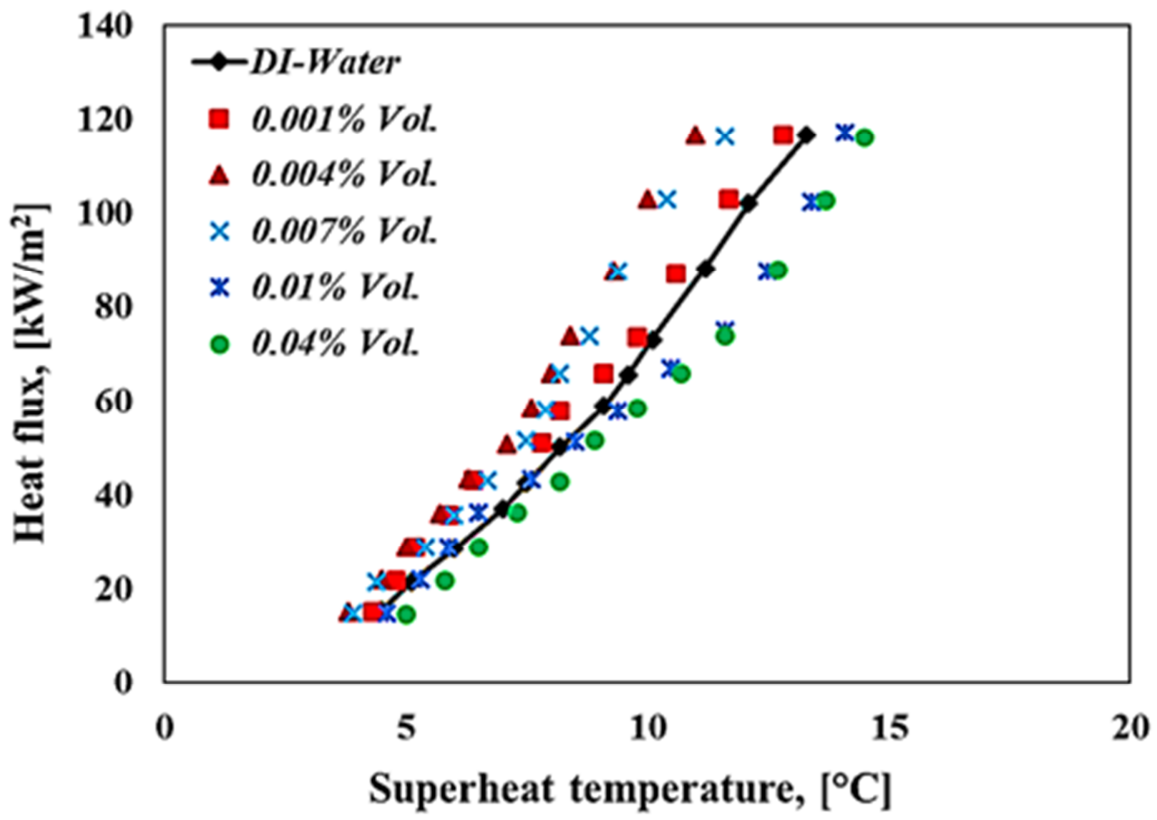

Fig. 4. Pool boiling curves of deionized water and magnesium oxide $\mathrm{MgO}$-based deionized water nanofluids at different volume concentrations

Fig. 5 depicts the pool boiling heat transfer coefficient against heat flux for deionized water and magnesium oxide nanoparticles based deionized water nanofluids at different volume concentrations. It can see from those curves that the pool boiling heat transfer coefficient considerably increased for nanofluids with volume concentration $0.001 \%, 0.004 \%$, and $0.007 \%$ Vol. compared to pool boiling heat transfer coefficient of deionized water. However, using concentration above $0.007 \% \mathrm{Vol}$. led to a reduction in the heat transfer coefficient of $\mathrm{MgO}$ nanofluids, especially at moderate and high heat fluxes. It was widely reported in the literature that the pool boiling heat transfer could be affected by the bulk properties of the liquid and surface modification during the presence of the nanoparticles during the nucleate boiling regime. Hence, in case of low concentrations, the results lead to enhancement of pool boiling heat transfer 
coefficient, and this improvement supposed that both effects contributed to improving the pool boiling behavior. The slightly increased thermal conductivity at volume concentration, i.e. $0.004 \%$ and $0.007 \%$ Vol. and the deposition of nanoparticles after a period of the boiling process resulted in improving the surface characteristics for horizontal heated tube in the present case. The average size of the magnesium oxide nanoparticles was in the range $70-100 \mathrm{~nm}$, while the average roughness for the heater was measured by surface profile meter to be $382 \mathrm{~nm}$ in this test. Hence, the deposition of nanoparticles creates new cavities, which led to increasing the nucleation sites, and in turn, more bubbles were formed during the nucleate pool boiling regime. The interaction and the mixing between the bubbles led to increasing the collision of these nanoparticles then increase the Brownian motion during the boiling process.

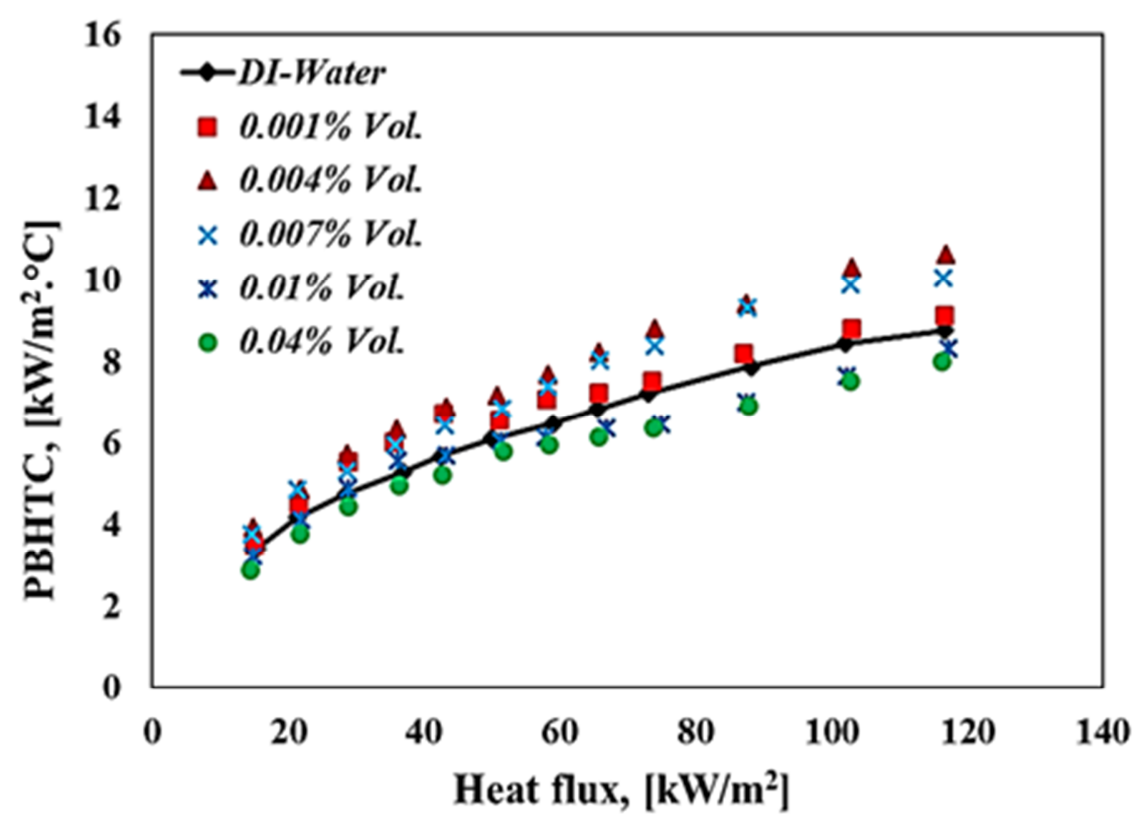

Fig. 5. Pool boiling heat transfer coefficient of deionized water and magnesium oxide $\mathrm{MgO}$-based deionized water nanofluids at different volume concentrations

Fig. 6 shows the pool boiling heat transfer coefficient enhancement ratio $\left(\mathrm{PBHTC}_{\mathrm{nf}} / \mathrm{PBHTC}_{\mathrm{water}}\right)$ relative to deionized water at various heat fluxes and volume concentration of magnesium oxide nanofluids. It can be seen that the maximum enhancement was (1.22) for volume concentration (0.004\% Vol.) at higher heat fluxes region. At the same time, there was a reduction in this ratio for high volume concentration used in this test of nanofluids. The reduction was attributed to the deposition of the nanoparticles during the pool boiling process even at low heat flux; stability of the nanofluid in this concentration was also a vital issue to contribute with this deterioration. However, it was found that the thermal resistance increased with an increase in the volume concentration of the $\mathrm{MgO}$ nanofluids above $0.007 \% \mathrm{Vol}$. This 
was due to the increase of deposition of nanoparticles on the heating surface, which formed a porous resistance layer on the wall, which may reduce the bubble creation followed by a reduction in the quantity of heat transfer from the heating surface to the bulk of the fluid and this trend was also observed in other related studies [21], [26].

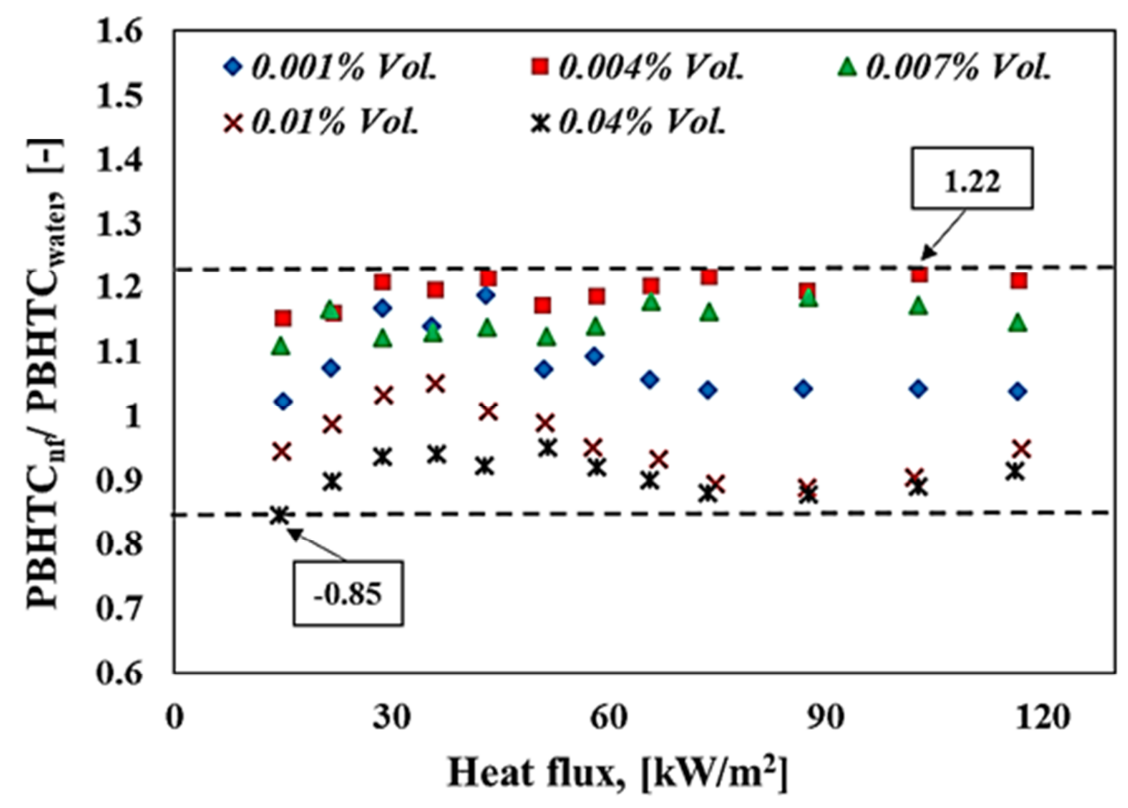

Fig. 6. Pool boiling heat transfer coefficient ratio of Magnesium oxide $\mathrm{MgO}$-based deionized water nanofluid to deionized water at various volumetric concentrations and applied heat fluxes

Fig. 7 depicts the maximum pool boiling heat transfer coefficient ratio of magnesium oxide $\mathrm{MgO}$-based deionized water nanofluid relative to deionized water at various volumetric concentrations. It can be seen that the maximum enhancement ratio was 1.22 at volume concentration $0.004 \%$ Vol. and the maximum reduction ratio was 0.85 at volume concentration $0.04 \%$ Vol. which considered as a higher concentration in this study. It can conclude from the results that the enhancement or reduction ratio during the pool boiling of nanofluids depends on the volume concentration of the nanofluid and also the surface modification during the deposition of nanoparticles on the heater surface. Moreover, the bubble interaction with suspended nanoparticles could be another parameter that could affect the boiling performance when using nanofluids.

\section{Conclusion}

In this study, the pool boiling heat transfer performance of deionized water and magnesium oxide nanoparticles based deionized water from the horizontal heated copper tube was experimentally investigated. The nanofluids were prepared at different volume concentrations and various applied heat fluxes were applied to test the pool 
boiling performance at atmospheric pressure conditions. The prepared nanofluids were checked to see the stability of the suspension after ultra-sonication processes and the stability was reasonably good at less for the experiment duration. The obtained results demonstrated that the pool boiling heat transfer coefficient enhancement ratio $\left(\mathrm{PBHTC}_{\mathrm{nf}} / \mathrm{PBHTC}_{\mathrm{water}}\right)$ was improved for volume concentrations, i.e. $0.001 \%$, $0.004 \%$, and $0.007 \%$ Vol., and the maximum enhancement ratio was 1.22 for concentration $0.004 \%$ Vol. while there was a deterioration in this ratio for concentrations, i.e. $0.01 \%$, and $0.04 \%$ Vol. and the maximum reduction was 0.85 compared to deionized water as the baseline case.

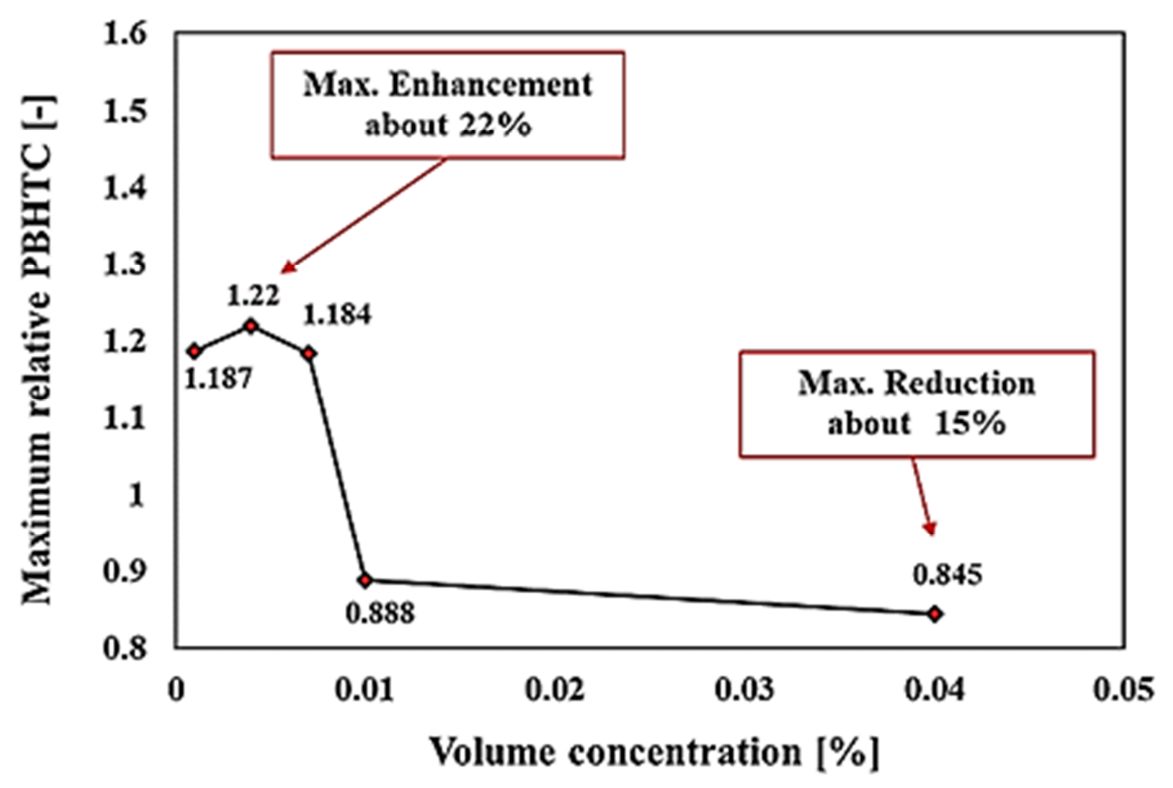

Fig. 7. Maximum pool boiling heat transfer coefficient ratio of Magnesium oxide MgO-based deionized water nanofluid concerning deionized water at various volumetric concentrations

\section{Acknowledgments}

The Authors would like to thanks the Hungary Government for their financial support represented in the Stipendium Hungaricum Scholarship. Besides, they would also like to thanks the Tempus Public Foundation in Hungary for their continuous administrative support from application to graduation. The Authors would also like to thank Dr. Czampa Miklós, István Rudy, and Sherwan M. Najm for their support throughout the experimental side. 


\section{Open Access statement}

This is an open-access article distributed under the terms of the Creative Commons Attribution 4.0 International License (https://creativecommons.org/licenses/by/4.0/), which permits unrestricted use, distribution, and reproduction in any medium, provided the original author and source are credited, a link to the CC License is provided, and changes - if any - are indicated. (SID_1)

\section{References}

[1] Kamel M. S., Sobhi M., Lezsovits F., Mahian O. Simulation of pool boiling of nanofluids by using Eulerian multiphase model, J. Therm. Anal. Calorim, 2019, doi:10.1007/s10973019-09180-X.

[2] Kamel M. S., Lezsovits F., Hussein A. M., Mahian O., Wongwises S. Latest developments in boiling critical heat flux using nanofluids: A concise review, Int. Commun. Heat Mass Transf, Vol. 98, 2018, pp. 59-66.

[3] Kamel M. S., Lezsovits F. Boiling heat transfer of nanofluids a review of recent studies, Therm. Sci, Vol. 23, No. 1, 2019, pp. 109-124.

[4] Kamel M. S., Lezsovits F., Hussein A. K. Experimental studies of flow boiling heat transfer by using nanofluids: A critical recent review, J. Therm. Anal. Calorim. Vol. 138, 2019, pp. 4019-4043.

[5] Jancskar I., Ivanyi A. Phenomenological hysteresis model for vapor-liquid phase transitions, Pollack Periodica, Vol. 3, No. 1, 2008, pp. 5-28.

[6] Choi S. U. S., Eastman J. A. Enhancing thermal conductivity of fluids with nanoparticles, $36^{\text {th }}$ International Mechanical Engineering Congress and Exhibition, San Francisco, CA US, 12-17 Nov 1995, pp. 99-105.

[7] Kamel M. S., Syeal R. A., Abdulhussein A. A. Heat transfer enhancement using nanofluids: A review of the recent literature, American J. of Nano Research and Applications, Vol. 4, No. 1, 2016, pp. 1-5.

[8] Kamel M. S., Lezsovits F. Simulation of nanofluids laminar flow in a vertical channel, Pollack Periodica, Vol. 13, No. 2, 2018, pp. 147-158.

[9] Pak B. C., Cho Y. I. Hydrodynamic and heat transfer study of dispersed fluids with submicron metallic oxide particle, Experimental Heat Transfer, Vol. 11, No. 2, 1998, pp. $151-170$.

[10] Hamilton R. L., Crosser O. K. Thermal conductivity of heterogeneous two-component systems, Ind. Eng. Chem. Fundam, Vol. 1, 1962, pp. 187-191.

[11] Chand R., Rana G., Hussein, A. K. Effect of suspended particles on the onset of thermal convection in a nanofluid layer for more realistic boundary conditions, International Journal of Fluid Mechanics Research, Vol. 42, No. 5, 2015, pp. 375-390.

[12] Yang Y. M., Maa J. R. Boiling of suspension of solid particles in water, Int. J. Heat Mass Transf. Vol. 27, No. 1, 1984, pp. 145-147.

[13] Das S. K., Putra N., Roetzel W. Pool boiling characteristics of nanofluids, Int. J. Heat Mass Transf. Vol. 46, No. 5, 2003, pp. 851-862.

[14] Trisaksri V., Wongwises S. Nucleate pool boiling heat transfer of TiO2-R141b nanofluids, Int. J. Heat Mass Transf. Vol. 52, No. 5-6, 2009, pp. 1582-1588.

[15] Suriyawong A., Wongwises S. Nucleate pool boiling heat transfer characteristics of TiO2water nanofluids at very low concentrations, Exp. Therm. Fluid Sci. Vol. 34, No. 8, 2010, pp. 992-999. 
[16] Cieśliński J. T., Kaczmarczyk T. Z. Pool boiling of water-A12O3 and water-Cu nanofluids on horizontal smooth tubes, Nanoscale Res. Lett. Vol. 6, No. 1, 2011, pages 1-9.

[17] Cieśliński J. T., Kaczmarczyk T. Z. The effect of pressure on heat transfer during pool boiling of water-A12O3 and water-Cu nanofluids on stainless steel smooth tube, Chem. Process Eng. Vol. 32, No. 4, 2011, pp. 321-332.

[18] Ahmed O., Hamed M. S. Experimental investigation of the effect of particle deposition on pool boiling of nanofluids, Int. J. Heat Mass Transf. Vol. 55, No. 13-14, 2012, pp. 3423-3436.

[19] Sarafraz M. M., Hormozi F. Experimental investigation on the pool boiling heat transfer to aqueous multi-walled carbon nanotube nanofluids on the micro-finned surfaces, Int. J. Therm. Sci. Vol. 100, 2016, pp. 255-266.

[20] Kiyomura I. S., Manetti L. L., da Cunha A. P., Ribatski G., Cardoso E. M. An analysis of the effects of nanoparticles deposition on characteristics of the heating surface and ON pool boiling of water, Int. J. Heat Mass Transf. Vol. 106, 2017, pp. 666-674.

[21] Karimzadehkhouei M., Shojaeian M., Şendur K., Mengüç M. P., Koşar A. The effect of nanoparticle type and nanoparticle mass fraction on heat transfer enhancement in pool boiling, Int. J. Heat Mass Transf. Vol. 109, 2017, pp. 157-166.

[22] Solangi K. H., Kazi S. N., Luhur M. R., Badarudin A., Amiri A., Sadri R., Zubir M. N. M., Gharehkhani S., Teng K. H. A comprehensive review of thermo-physical properties and convective heat transfer to nanofluids, Energy, Vol. 89, 2015, pp. 1065-1086.

[23] Rohsenow W. M. Method of correlating heat transfer data for surface boiling of liquids, Technical Report, MIT, 1952, pages 31.

[24] Gorenflo D., Kenning D. H2 Pool Boiling, in VDI heat atlas, VDI-Buch, Springer, 2010.

[25] Lemmon E. W., McLinden M. O., Friend D. G. Thermophysical properties of fluid systems in: NIST Chemistry WebBook, NIST Standard Reference Database, No. 69, 2019.

[26] Sarafraz M. M., Arya H., Saeedi M., Ahmadi D. Flow boiling heat transfer to MgOtherminol 66 heat transfer fluid: Experimental assessment and correlation development, Appl. Therm. Eng. Vol. 138, 2018, pp. 552-562. 